\title{
The decreased expression of protease-activated receptor 4 in esophageal squamous carcinoma
}

\author{
S. $\mathrm{LEE}^{1}$, P. JIANG ${ }^{2}$, W. WANG ${ }^{3}$, W. FENG ${ }^{1}$, G. YU $\mathrm{U}^{1, \star}$ \\ ${ }^{1}$ Department of Biochemistry and Molecular Biology, Kunming Medical University, Kunming, Yunnan 650500, China; ${ }^{2}$ Department of Pathol- \\ ogy, Kunming Medical University, Kunming, Yunnan 650500, China; ${ }^{3}$ Department of Chest Surgery, the Third Affiliated Hospital of Kunming \\ Medical University, Kunming 650106, China
}

*Correspondence: yuguoyu2011@hotmail.com

Received November 28, 2013 / Accepted February 5, 2014

\begin{abstract}
Protease-activated receptors (PARs) are a unique family of G-protein coupled receptors. PAR4, a member of PARs family, was reported to be related to the development of cancers. Whether PAR4 plays a role in the progress of esophageal squamous cancer is unknown. In this study, differential expression of PAR4 in esophageal squamous cancer was measured by real-time PCR $(n=28)$, western blot and tissue microarrays $(n=78)$. The results showed that PAR4 expression was remarkably decreased in esophageal squamous cancer tissues compared with the matched noncancerous tissues, especially in low differentiation and positive distant metastasis carcinoma tissues. Furthermore, the methylation level of PAR4 promoter in esophageal cancer cells and normal epithelial cells was determined. Human esophageal cancer cells TE-1 displayed significant hypermethylation of $19 \mathrm{CpG}$ sites, but pronounced hypomethylation of the sites in esophageal epithelial cells HEEpiC. The results suggested that down-regulation expression of PAR4 occurs frequently in esophageal squamous cancers, and the loss of PAR4 expression may partly result from hypermethylation of the PAR4 promoter. That PAR4 expression difference in tumor progression possibly makes PAR4 become a molecular mark of tumor diagnosis.
\end{abstract}

Key words: protease-activated receptor 4, esophageal squamous cancer, decreased expression, methylation

Protease-activated receptors (PARs) are a unique family of G-protein coupled receptors (GPCRs) [1]. Four members have been cloned in human, namely, PAR1, PAR2, PAR3, PAR4, sharing the common mechanism of activation by proteolysis [2]. PAR4 differential expression occurs in many malignant tumors, such as gastric cancer, liver cancer, colon cancer, lung cancer, breast cancer and prostate cancer [3]. Some studies revealed that PAR4 is highly expressed in colon cancer and liver cancer cells, and PAR4 induces the proliferation and migration of cancer cells $[4,5]$. Other research revealed that PAR4 is lowexpressed in gastric carcinoma and even no expression in some poor-differentiated and high in gastric cancer with lymph node metastases [6]. However, the differential expression of PAR4 in esophageal cancer has not been investigated.

Esophageal squamous cell carcinoma (ESCC), accounting for around $90 \%$ of esophageal cancers, is the major histological form of esophageal cancer in East Asian countries [7]. Due to the difficulties in early diagnosis and treatment, ESCC becomes a highly aggressive malignancy with a poor prognosis [8]. Thus it is important to find a potentially useful and early diagnostic and treatment indicator. An association between PARs and esophageal cancer has been implicated. PAR1 was positive expressed in $68.2 \%$ esophageal cancer tissues, while no significant expression in normal esophageal squamous epithelium. And PAR1 overexpression was significantly associated with tumor node metastasis (TNM) stage and regional lymph node involvement [9]. Similarly, PAR2 expression was increased in primary esophageal squamous cell carcinoma compared with the normal esophageal epithelial cell. And PAR2 expression level in tumor tissues was significantly correlated with the clinical stage, histological grade and prognosis [10]. But it is still not clear about the molecular mechanism underlying the progression of esophageal cancer.

In this study, we discussed the differential expression of PAR4 in esophageal squamous cell carcinoma. And the results showed that the expression of PAR4 is reduced in esophageal squamous cancer tissues, and the down-regulation expression was partly resulted from the increased methylation level of PAR4 promoter. 


\section{Patients and methods}

Patients and samples. Tissues were taken from the tumor and a tumor-free location that was at least $6 \mathrm{~cm}$ from the tumor in the Third Affiliated Hospital of Kunming Medical University. The non-neoplastic tissue was confirmed by histological assessment. Immediately after removal, all tissues for molecular analysis were put in liquid nitrogen and stored at $-80^{\circ} \mathrm{C}$ until use. Esophageal cancer tissue microarray representing 78 esophageal cancers with their non-neoplastic resection margins [11] were from Shanghai Outdo Biochip Center (Shanghai, China).

Cell culture. Human esophageal epithelial cells HEEpiC and esophageal cancer cells TE-1 were obtained from ATCC. HEEpiC cells were cultured in EpiCM2 (Shanghai, China) and Ham's F12 containing 10\% fetal calf serum (FCS) and supplied with $100 \mathrm{U} / \mathrm{ml}$ penicillin, and $100 \mathrm{mg} / \mathrm{ml}$ streptomycin. TE-1 cells were cultured in RPMI-1640 and DMEM media, respectively. The cells were grown in a humidified atmosphere with $5 \% \mathrm{CO} 2$ at $37^{\circ} \mathrm{C}$. The whole volume of cells was collected and subjected to RT-PCR and methylation analysis.

RNA extraction and polymerase chain reaction (PCR). RNA extraction and the first-strand cDNA synthesis were performed as previously described [12]. For semi quantitative reverse-transcription PCR (RT-PCR), the primers used were as follows: PAR4 (244 bp product): 5'-CCTTCATCTACTACTACGTGTCG-3' (forward) and 5'ACTGGAGCAAAGAGGAGTGG-3'(reverse); glyceraldehyde 3-phosphate dehydrogenase (GAPDH) (308 bp product): 5'-TCGGAGTCAACGGATTTGGTCGTA-3'(forward) and 5'-AGCCTTCTCCATGGTGGTGAAGA-3'(reverse). Amplicons were separated by electrophoresis in $2 \%$ agarose gel, stained with ethidium bromide and viewed under ultraviolet illumination. The identity of PCR product was confirmed by DNA sequencing.

Quantitative real-time PCR (qPCR) was performed with a continuous fluorescence detector (Opticon Monitor, BioRad, Hercules, CA, USA). qPCR reaction was carried out using a SYBR Green real-time PCR kit (TaKaRa, Dalian, China) with the condition as the following: initial denaturation at $95^{\circ} \mathrm{C}$ for 1 min, followed by 40 cycles at $95^{\circ} \mathrm{C}$ for $15 \mathrm{~s}, 60^{\circ} \mathrm{C}$ for $15 \mathrm{~s}$, and $72^{\circ} \mathrm{C}$ for $20 \mathrm{~s}$. The primers used for amplifying human PAR4 (147 bp) were 5'-CCTTCATCTACTACTACTACGTGTCG-3'(forward) and 5'- ACTGGAGCAAAGAGGAGTGG-3'(reverse). Amplification of GAPDH (107 bp), with the primers 5'-ATGGGGAAGGTGAAGGTCG-3'(forward) and 5'-GGGGTCATTGATGGCAACAATA-3'(reverse), was examined in parallel as an internal control. The identity of the PCR products was confirmed by DNA sequencing. Each sample was run three times. No template controls (no cDNA in PCR) were run to detect unspecific or genomic amplification and primer dimerization. Fluorescence curve analysis was carried using Opticon Monitor software. Relative quantitative evaluation of PAR4 levels were performed by E-method and expressed as a ratio of the transcript of PAR4 to GAPDH in the tumor tissue divided by a similar ratio in the non-neoplastic tissue of the same patient [13].

Tissue immunohistochemistry. Tissue immunohistochemistry was performed as described previously [4]. Briefly, antigen retrieval was performed by heating in an autoclave at $121^{\circ} \mathrm{C}$ for $5 \mathrm{~min}$. Dewaxed sections were pre-incubated with blocking serum and then incubated overnight with the anti-human PAR4 antibody (C-20, 1:1200; Santa Cruz Biotechnology, Santa Cruz, CA, USA) at $4^{\circ} \mathrm{C}$. Specific binding was detected by a streptavidin-biotin-peroxidase assay kit (Maxim, Fujian, China). The section was counterstained with Harris hematoxylin. Direct microscopic micrographs were captured using a Leica DFC320 camera controlled by Leica IM50 software (Leica, Germany). Sections incubated with normal goat IgG were served as a negative control and the negative immunohistochemical control was devoid of any detectable immunolabeling. Specificity of the antibodies for PAR 4 was confirmed by pre-incubation overnight at $4^{\circ} \mathrm{C}$ with its respective antigen (Santa Cruz) in a 20-fold molar excess of antigen to antibody. Pre-incubation with PAR4 antigen resulted in an absence of immunolabeling.

Immunohistochemical staining was assessed semiquantitatively by measuring both the intensity of the staining $(0,1$, 2 , or 3$)$ and extent of staining $(0,0 \% ; 1,0-10 \% ; 2,10-50 \% ; 3$, $50-100 \%)$. The scores for the intensity and extent of staining were multiplied to give a weighted score for each case (maximum possible, 9). For the statistical analysis, the weighted scores were grouped into two categories where scores of 0-3 were considered negative and 4-9 positive [14].

Western blotting. Tissue samples were homogenized in radioimmunoprecipitation assay buffer (Sigma) with protease inhibitors cocktail (Sigma). The protein concentration was determined by a protein assay kit (Bio-Rad). Samples (containing $50 \mu \mathrm{g}$ of protein) were loaded on an SDS-polyacrylamide gel electrophoresis (SDS-PAGE) gel and then electro-transferred onto a PVDF membrane. The membrane was subsequently blocked with $3 \%$ bovine serum albumin (BSA) and incubated with anti-PAR4-antibody (C-20, 1:3500, $4^{\circ} \mathrm{C}$, overnight) and relative secondary antibody. Protein bands were visualized with Super Signal reagents (Pierce, Rockford, IL, USA). Specificity of the anti-PAR4 antibody was confirmed by pre-incubation with its antigenic peptide in a 20-fold molar excess of antigen to antibody. Preincubation with PAR4 antigen resulted in an absence of PAR4 band.

Bisulfite sequencing. Genomic DNA from cell lines was isolated with the Universal Genomic DNA Extraction Kit (TaKaRa) and bisulfiteconverted using the Clontech EpiXplore $^{\mathrm{TM}}$ Methyl Detection Kit (TaKaRa). PAR4 promoter sequences were amplified from bisulfite-converted DNA by PCR, purified from agarose gels and subcloned into the pBackZero T Vector (TaKaRa). For each sample, 11 individual clones were sequenced to identify methylated cytosine residues. PCR primer sequences (forward and reverse) were 5' -TTTAAGGGTGATTTTAGGAAAGGTTTAGAG-3' and 5'-ACTATAACСТСAАACTTCСТАССТC-3'. 


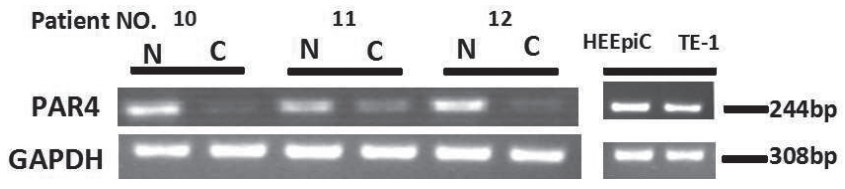

Figure1. Expression of PAR4 in esophageal squamous cancer tissue and cells was measured by RT-PCR. The matched normal $(\mathrm{N})$ and cancerous (C) tissues from each patient $(n=3)$, HEEpiC and TE-1 cells were analyzed by RT-PCR using PAR4- and GAPDH- specific primers. After the samples were normalized to GAPDH levels, the results of RT-PCR showed significantly decreased mRNA levels of PAR4 in cancer tissues compared to normal tissues (three of three), and PAR4 expression was also decreased in esophageal cancer cell TE-1 compared with HEEpiC cells.

Statistical analysis. All statistical analyses were performed by the SPSS 11.0 software (SPSS Inc., Chicago, IL, USA). The Fisher's exact test and chi squared test for the significance of correlations between PAR4 expression and clinicopathological parameters (Tables 1 and 2). Differences in the numerical data between the two paired groups were evaluated using the paired Wilcoxon test (Fig. 2). The level of statistical significance was set at the level of $\mathrm{p}<0.05$.

Table 1. Association between the mRNA levels of PAR4 with clinic-pathologic data in esophageal cancer patients.

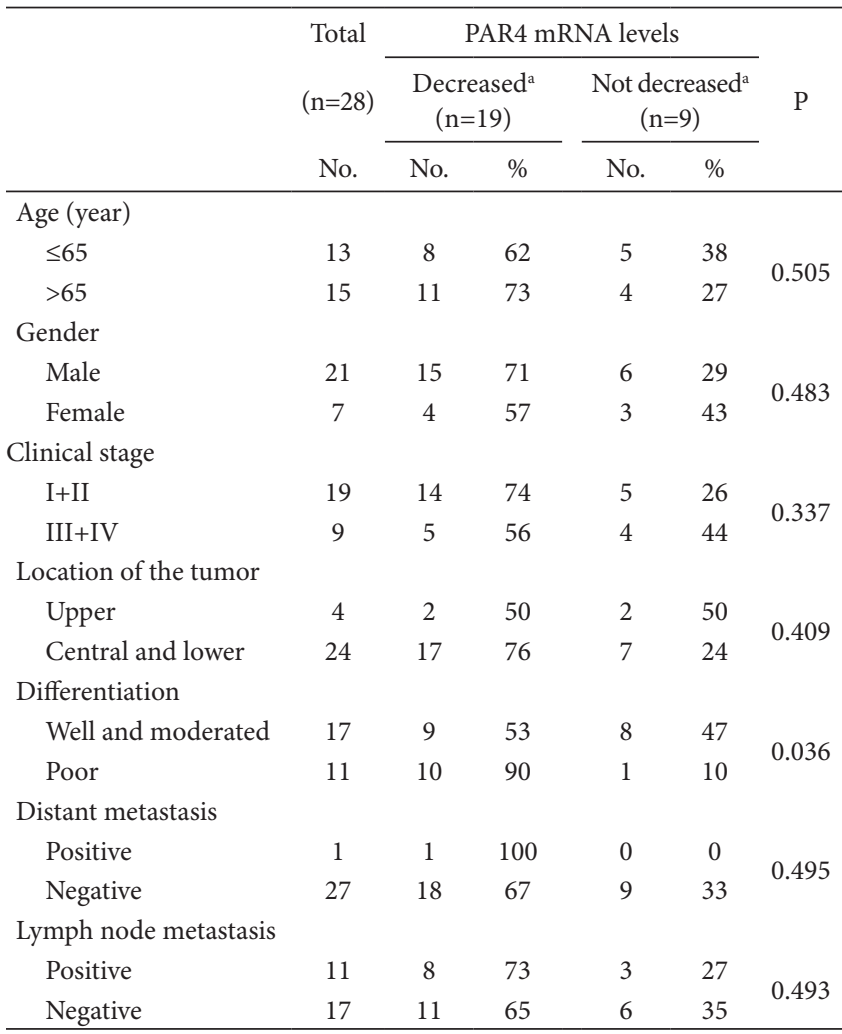

a The decreased folds of " $>21$ " was defined as "decreased", and " $\leq 2^{1}$ " was "not decreased"
Results

PAR4 mRNA was down-regulated frequently in esophageal squamous cancers and the correlation with clinicopathological parameters. As shown in Fig.1, RT-PCR was performed on matched normal and cancer tissue specimens of 3 patients selected randomly $(n=3)$. The results showed that mRNA levels of PAR4 in cancer were significantly decreased compared to relative normal tissues after the samples were normalized to GAPDH levels. And PAR4 expression was also decreased in esophageal cancer cell line TE-1 compared to normal esophageal epithelial cell HEEpiC.

The differential expression of PAR4 mRNA was further examined by real-time PCR analysis in 28 esophageal squamous cancer tissue samples. We compared the primary tumor with the matched non-neoplastic tissues. Overall down-regulated PAR4 expression was detected in 68\% (19 of 28) of esophageal cancer tissues. PAR4 mRNA was reduced $14.7 \pm 3.5$ fold (mean \pm SEM) in esophageal squamous cancers $(\mathrm{p}=0.001$, paired

Table 2. Association between the protein levels of PAR4 with histopathologic features of esophageal cancer

\begin{tabular}{|c|c|c|c|c|c|c|}
\hline & \multirow{3}{*}{$\begin{array}{c}\text { Total } \\
(\mathrm{n}=78) \\
\text { No. }\end{array}$} & \multicolumn{4}{|c|}{ PAR4 mRNA levels } & \multirow{3}{*}{$\mathrm{P}$} \\
\hline & & \multicolumn{2}{|c|}{$\begin{array}{c}\text { Decreased }^{a} \\
\quad(n=55)\end{array}$} & \multicolumn{2}{|c|}{$\begin{array}{l}\text { Not de- } \\
\text { creased }^{a} \\
(n=23)\end{array}$} & \\
\hline & & No. & $\%$ & No. & $\%$ & \\
\hline \multicolumn{7}{|l|}{ Age (year) } \\
\hline$\leq 65$ & 41 & 25 & 61 & 16 & 39 & \multirow{2}{*}{0.052} \\
\hline$>65$ & 37 & 30 & 81 & 7 & 19 & \\
\hline \multicolumn{7}{|l|}{ Gender } \\
\hline Male & 58 & 42 & 72 & 16 & 28 & \multirow{2}{*}{0.531} \\
\hline Female & 20 & 13 & 65 & 7 & 35 & \\
\hline \multicolumn{7}{|l|}{ Clinical stage } \\
\hline $\mathrm{I}+\mathrm{II}$ & 52 & 35 & 67 & 17 & 33 & \multirow{2}{*}{0.38} \\
\hline III+IV & 26 & 20 & 77 & 6 & 23 & \\
\hline \multicolumn{7}{|l|}{ Tumor location } \\
\hline Upper & 6 & 3 & 50 & 3 & 50 & \multirow{2}{*}{0.251} \\
\hline Central and lower & 72 & 52 & 75 & 20 & 25 & \\
\hline \multicolumn{7}{|l|}{ Differentiation } \\
\hline Well/moderated & 56 & 35 & 63 & 21 & 37 & \multirow{2}{*}{0.013} \\
\hline Poor & 22 & 20 & 90 & 2 & 10 & \\
\hline \multicolumn{7}{|l|}{ Distant metastasis } \\
\hline Positive & 9 & 9 & 100 & 0 & 0 & \multirow{2}{*}{0.039} \\
\hline Negative & 69 & 46 & 67 & 23 & 33 & \\
\hline \multicolumn{7}{|l|}{ Lymph node metastasis } \\
\hline Positive & 10 & 7 & 70 & 3 & 30 & \multirow{2}{*}{0.616} \\
\hline Negative & 68 & 48 & 71 & 20 & 29 & \\
\hline
\end{tabular}

a The immunohistochemical results was determined on the basis of comprehensive score of positive cell number and staining intensity, and the 0-3 scores was treated as decreased, and the 4-9 scores was treated as not decreased. Abbreaviation: PARs: protease-activated receptors, GPCRs: G-protein coupled receptors, ESCC: Esophageal squamous cell carcinoma, TNM: tumor node metastasis, FCS: fetal calf serum, qPCR: quantitative real-time PCR, 
Tumor differentiation
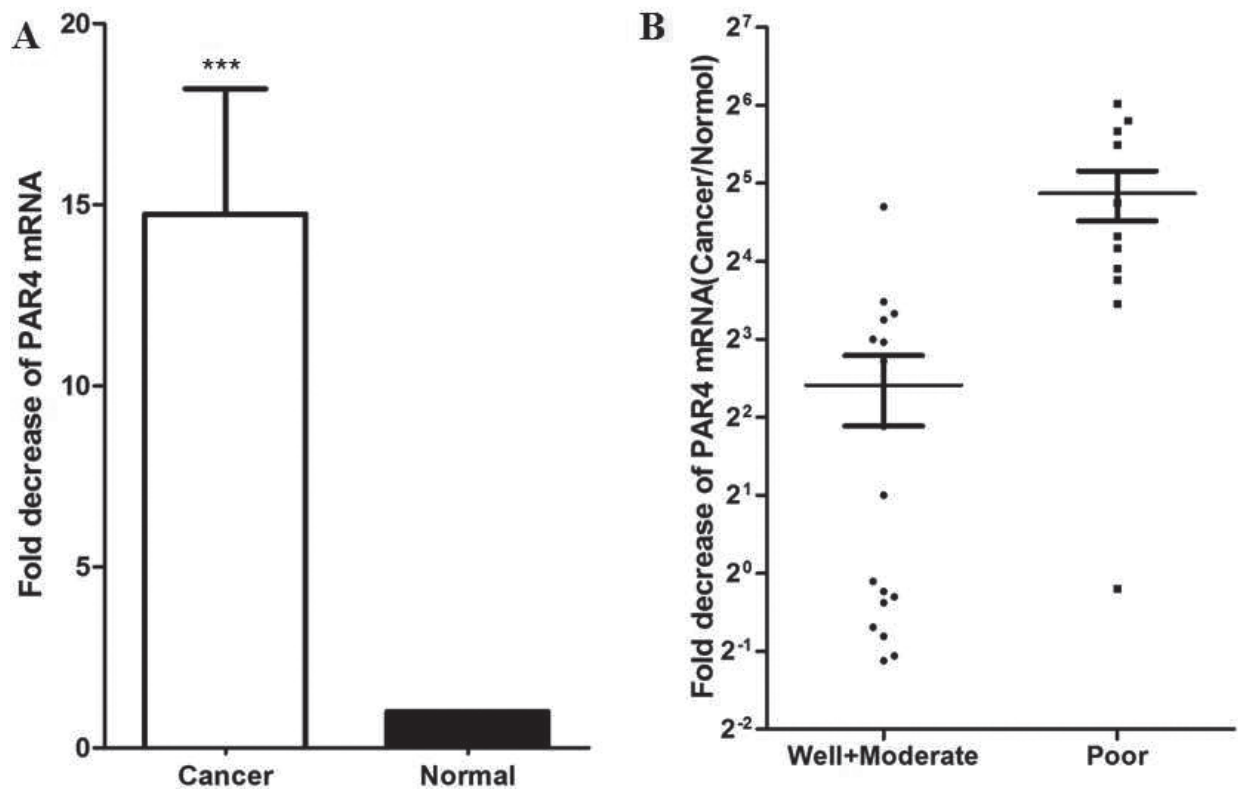

Figure 2. Expression of PAR4 mRNA in esophageal squamous cancers compared with non-neoplastic resection margins. Expression of PAR4 was measured in 28 esophageal squamous cancer patients by real-time PCR. (A) PAR4 mRNA was reduced in esophageal cancer tissues compared with the normal (normalized to 1). (B) PAR4 mRNA was decreased 68\% (19 of 28) in esophageal squamous cancers, while it was decreased in $91 \%$ (10 of 11 ) poor-differentiated cancers and $53 \%(9$ of 17$)$ well-/moderated-differentiated cancers. Mean fold decrease in the tumor tissue relative to non-neoplastic esophageal tissue was shown. Bars, SEM. The decreased folds of " $>2$ " were defined as "decreased", whereas decreased folds of " $\leq 2$ " were defined as "not decreased".

Wilcoxon test) compared with the normal tissues (normalized to 1) (Fig. 2A). Next we investigated the clinical significance of loss of PAR4 expression on clinic-pathological data. There only existed significant differences of PAR4 mRNA expression in poor-differentiated tumors versus well-/moderated-differentiated tumors ( $\mathrm{p}=0.036$, chi squared test) (Table 1$)$. In details, PAR4 mRNA was reduced $29.33 \pm 6.4$ fold (mean \pm SEM) in 11 poor-differentiated cancers $(\mathrm{p}=0.001$, paired Wilcoxon test $)$ and $5.31 \pm 1.6$ fold $(p=0.0003)$ in 17 well-/moderateddifferentiated cancers (Fig. 2B).

Protein levels of PAR4 were frequently decreased in the esophageal cancer tissues and the correlation with histopathologic features. Using Western blotting, we found that PAR4 expression was reduced significantly in esophageal cancer comparing with the matched nonmalignant esophageal tissue. PAR4 down-regulation expression was also observed in esophageal cancer cell line TE-1, while the protein expression was high in human esophageal epithelial cell HEEpiC (Fig. 3)

We further used immunohistochemical assay to assess the in vivo status of PAR4 expression in esophageal squamous cancerous and normal tissues. PAR4 was expressed at high level in non-neoplastic esophageal squamous epithelial cells (Fig. 4A). However, in cancerous tissue, PAR4 expression was significantly reduced and even lost. In details, PAR4 was mainly stained in well-differentiated esophageal cancers cells (Fig. 4B), low-expressed in the moderate-differentiated esophageal cancers cells (Fig. 4C), and even no expression in the poor-differentiated esophageal cancers (Fig. 4D), suggesting PAR4 expression was related to the progress of esophageal squamous cancers. Next, we investigated the correlation between loss of PAR4 expression and clinicpathological parameters. PAR4 expression was decreased in $70 \%$ (55 of 78) of esophageal squamous cancer tissues.

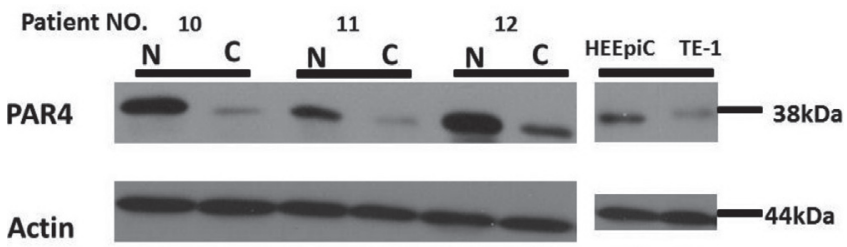

Figure 3. Western blot analysis of PAR4 expression of esophageal squamous cancer tissues and cells. Western blotting analysis tissue lysates from 3 cases of esophageal cancer $(\mathrm{C})$ and relevant non-neoplastic mucosa tissues $(\mathrm{N})$; And analysis TE-1 and normal esophageal epithelial cell HEEpiC. The significant loss of PAR4 expression was observed in the cancerous tissues compared with the matched normal tissues, and in esophageal cancer cell line TE-1 compared with HEEpiC cell. The expression of actin was served as a control. 

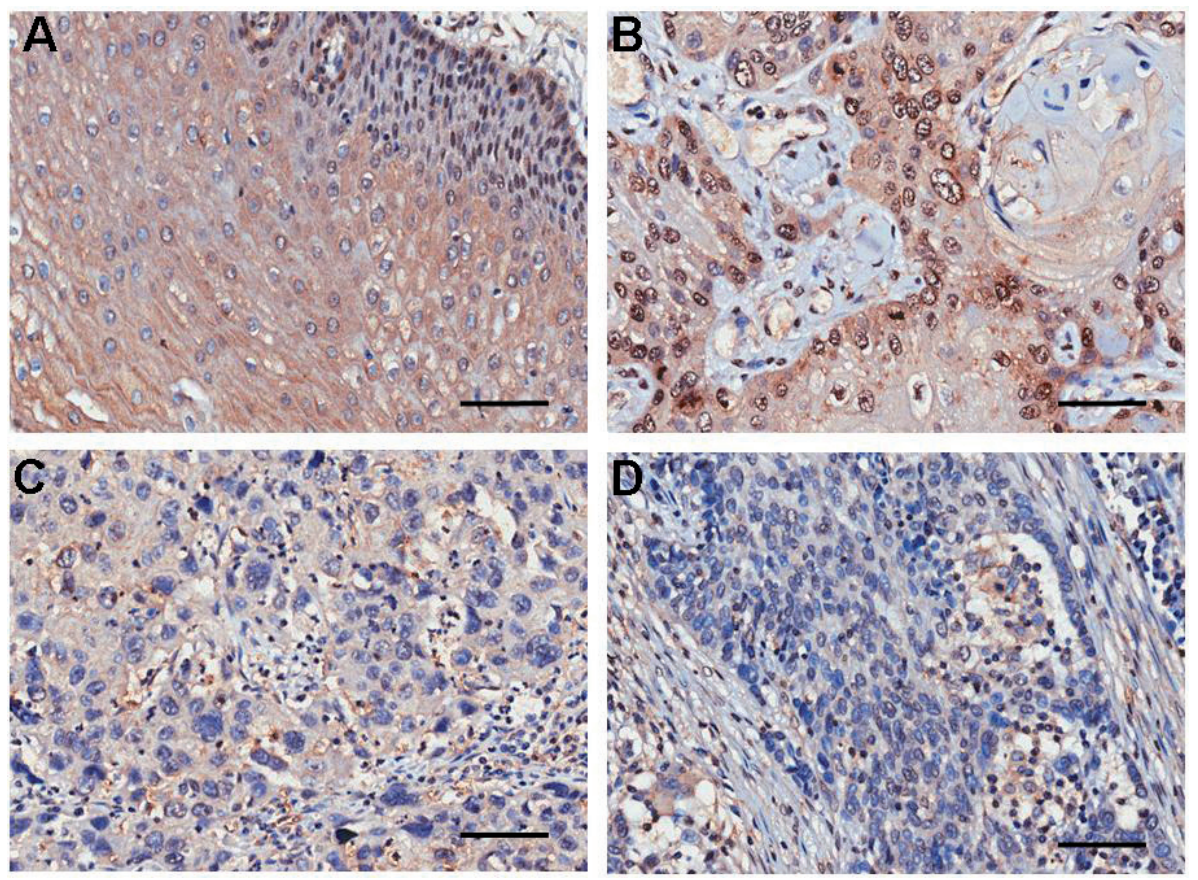

Figure 4. Representative photomicrographs of immunohistochemical staining for PAR4 in paraffin sections of esophageal tissues. (A) normal esophageal epithelial tissues, PAR4 was highly expressed in the normal squamous epithelial cells, and the protein mainly located in the cytoplasm and membrane. (B) well-differentiated squamous cell carcinoma: PAR4 was positive expressed in cytoplasm, membrane and nucleus of well-differentiated esophageal squamous cancer cells. (C) moderated-differentiated squamous cell carcinoma: parts of the cancer cells exhibited PAR4 positive expression and the expression was mainly located in the cytoplasm and membrane. (D) poor-differentiated squamous cell carcinoma: less expression was seen and even no expression in poor-differentiated cancer cells.

${ }^{a}$ The immunohistochemical results was determined on the basis of comprehensive score of positive cell number and staining intensity, and the 0-3 scores was treated as decreased, and the 4-9 scores was treated as not decreased.

And PAR4 down-regulation expression was associated with tumor differentiation and distant metastasis. In details, PAR4 expression was decreased in $90 \%$ of poor-differentiated cancers and in $63 \%$ of well-/moderated-differentiated cancers ( $\mathrm{p}=0.013$, chi squared test); PAR4 expression was decreased in $100 \%$ of distant metastasis cancers, and in $67 \%$ of no distant metastasis cancers ( $\mathrm{p}=0.039$, chi squared test) (Table 2).

Analysis of the methylation level of promoter region of PAR4 gene in esophageal cancer cell. Using the genomic bi- sulfite sequencing method, we analyzed $19 \mathrm{CpG}$ sites of PAR4 gene in human esophageal epithelial cell line HEEpiC and human esophageal cancer cell line TE-1. TE-1 cells displayed hypermethylation of the $19 \mathrm{CpG}$ sites, and the total methylation rate is $94.7 \%$. However, the total methylation rate of PAR4 is 35.4\% in $19 \mathrm{CpG}$ sites of HEEpiC cells, which showed pronounced promoter hypomethylation compared with the esophageal cancer cell (Fig. 5), suggested PAR4 down-regulated expression possibly resulted from the hypermethylation of gene promoter region.

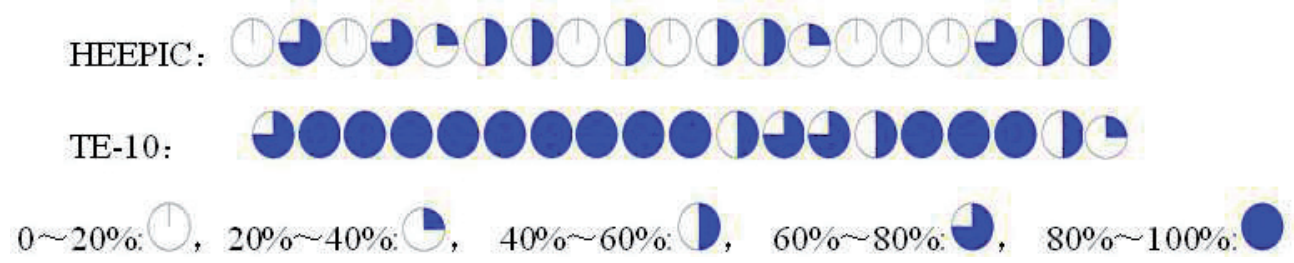

Figure 5. Genomic bisulfite sequencing of the promoter region of the PAR4 gene in esophageal cancer cells. PAR4 promoter methylation level in DNA from TE-1 and HEEpiC cells, average methylation at each analyzed CpG site in the PAR4 promoter is indicated based on bisulfite sequencing of 11 individual clones. 


\section{Discussion}

PARs have been demonstrated to be implicated in tumor growth, invasion and metastasis in several malignancies [15]. PAR1, widely expressed in human cancers, promotes the transformation and adhesion of pancreatic cancer cells as well as the invasion and metastasis of oral adenocarcinoma, colon cancer and breast cancer cells [16-18]. PAR2 is closely related to the growth and invasion of nasopharyngeal cancer, breast cancer, gastric cancer, colon cancer, prostate cancer and pancreatic cancer [19-21]. In fact, PAR1 and PAR2 were implicated to be overexpressed in the progress of ESCC, and the expression level serves as the possible prognostic marker only because the protein high expression strong correlates with tumor stage $[22,23]$. The role of PAR3 and PAR4 in cancer development is not clear. The latest research shows that PAR4 expression was remarkably decreased in gastric cancer tissues as compared with the matched noncancerous tissues, especially in positive lymph node or low differentiated cancers [6]. Jiang et.al reported that PAR4 down-regulation expression was found in lung adenocarcinoma and PAR4 decreased expression was associated with a more clinically aggressive phenotype, suggesting that PAR4 may act as a tumor suppressor in lung adenocarcinoma [24]. However, PAR4 was over-expressed in colorectal cancer [25] and liver cancer [20], and the up-regulation expression of PAR4 contributed to the proliferation of cancer cells [26]. Further, PAR4 agonists can induce calcium influx and promote the proliferation of colon cancer cells through ErbB2 transcriptional activation and Src kinase pathway [26]. The results indicated that PAR4 plays different roles in progression of different cancers. In our research, we firstly presented some fundamental data about PAR4 expression in esophageal squamous cancer. PAR4 expression was decreased frequently in esophageal squamous cancer using RT-PCR, real-time PCR, Western blotting, and the immunohistochemical assays. And PAR4 decreased expression was related to cell differentiation and positive distant metastasis. Esophageal squamous cancer is one of the least studied and deadliest cancers worldwide because of fast progress, easy metastasis and poor prognosis [27], and its histological grade determines its diagnosis, treatment and survival rate [28]. In this study, we noted that PAR4 reduced expression and even no expression was found in the advanced esophageal cancer, such as poor-differentiated cancers and positive distant metastasis cancers, indicating that PAR4 plays tumor suppressing role in the development of esophageal squamous cancer. And real-time PCR and immunostaining results showed that there exists significant correlation between PAR4 down-regulation expression and tumor poor- differentiation; Similarly immunostaining results also revealed the significant correlation between PAR4 down-regulated expression and distant metastasis, while real-time PCR didn't show the significance. The inconsistent results possibly resulted from the different tissue samples and the less number of tissues analyzed by real-time PCR. In brief, PAR4 might be a potential marker for esophageal squamous carcinoma diagnosis and treatment.
The phenotype of cancerous cell may arise either from genetic sequence mutations that disrupt gene function or epigenetic events that may alter the heritable state of gene expression [29]. The main epigenetic modification of genome is methylation of cytosine residues within the context of 'CpG islands' in the promoter regions, which will lead to transcriptional silencing through a complex process involving histone deacetylation and chromatin condensation, and finally results to lost of gene expression [30]. And the alterations in DNA methylation level are a fundamental molecular change associated with the neoplastic process and have important biologic implications for tumor initiation and progression [31]. In our previous study, we found that PAR4 expression was decreased in the gastric carcinoma, and the down-regulation expression was partly resulted from the hypermethylation of CpG sites in gene promoter region [6]. Interestingly, at the present study, we found that the promoter $\mathrm{CpG}$ sites were hypermethylated in esophageal cancer cell TE-1 with decreased PAR4 expression, while the $\mathrm{CpG}$ sites were hypomethylated of promoter in normal esophageal epithelial cell HEEpiC with PAR4 high-level expression. These results indicated that the down-regulation expression of PAR4 in esophageal squamous was partly resulted from the hypermethylation of $\mathrm{CpG}$ sites in gene promoter region.

In conclusion, we show that PAR4 is frequently downregulated in esophageal squamous cancer and the decreased expression was associated with tumor differentiation and distant metastasis. Further the aberrant DNA methylation of promoter CpG sites is possibly a mechanism of PAR4 downregulation expression. These results might provide valuable insights for understanding molecular mechanism of carcinogenesis, progression and metastasis of esophageal cancer.

Acknowledgements: This work was supported by the Chinese National Natural Science Foundation (81160302); Yunnan Province Science and Technology Department Basic Research Foundation (2011FZ109).

\section{References}

[1] COUGHLIN S R. Thrombin signalling and protease-activated receptors. Nature. 2000; 407: 258-264. http://dx.doi. org/10.1038/35025229

[2] OSSOVSKAYA V S , BUNNETT N W. Protease-activated receptors: contribution to physiology and disease. Physiol Rev. 2004; 84: 579-621. http://dx.doi.org/10.1152/ physrev.00028.2003

[3] ELSTE A P, PETERSEN I . Expression of proteinase-activated receptor 1-4 (PAR 1-4) in human cancer. J Mol Histol . 2010; 41: 89-99. http://dx.doi.org/10.1007/s10735-010-9274-6

[4] GRATIO V, WALKER F, LEHY T, LABURTHE M, DARMOUL D . Aberrant expression of proteinase-activated receptor 4 promotes colon cancer cell proliferation through a persistent signaling that involves Src and ErbB-2 kinase. Int J Cancer. 2009; 124: 1517-1525. http://dx.doi.org/10.1002/ ijc. 24070 
[5] KAUFMANN R, RAHN S, POLLRICH K, HERTEL J, DITTMAR Y, et al. Thrombin-mediated hepatocellular carcinoma cell migration: cooperative action via proteinase-activated receptors 1 and 4. J Cell Physiol. 2007; 211: 699-707. http:// dx.doi.org/10.1002/jcp.21027

[6] ZHANG Y, YU G, JIANG P, XIANG Y, LI W, et al. Decreased expression of protease-activated receptor 4 in human gastric cancer. Int J Biochem Cell Biol . 2011; 43: 1277-1283. http:// dx.doi.org/10.1016/j.biocel.2011.05.008

[7] LV L, PAN K, LI X D, SHE K L, ZHAO J J, et al. The accumulation and prognosis value of tumor infiltrating IL-17 producing cells in esophageal squamous cell carcinoma. PLoS One. 2011; 6: e18219. http://dx.doi.org/10.1371/journal.pone.0018219

[8] ENZINGER P C , MAYER R J ESOPHAGEAL CANCER. N Engl J Med . 2003; 349: 2241-2252. http://dx.doi.org/10.1056/ NEJMra035010

[9] RIBEIRO F S, SIMAO T A, AMOEDO N D, ANDREOLLO $\mathrm{N}$ A, LOPES L R, et al. Evidence for increased expression of tissue factor and protease-activated receptor-1 in human esophageal cancer. Oncol Rep . 2009; 21: 1599-1604.

[10] WANG Y, GU Y, LUCAS M J. Expression of thrombin receptors in endothelial cells and neutrophils from normal and preeclamptic pregnancies. J Clin Endocrinol Metab . 2002; 87: 3728-3734. http://dx.doi.org/10.1210/jcem.87.8.8727

[11] KONONEN J, BUBENDORF L, KALLIONIEMI A, BARLUND M, SCHRAML $P$, et al. Tissue microarrays for high-throughput molecular profiling of tumor specimens. Nat Med . 1998; 4: 844-847. http://dx.doi.org/10.1038/ nm0798-844

[12] LIU S B, HE Y Y, ZHANG Y, LEE W H, QIAN J Q, et al. A novel non-lens betagamma-crystallin and trefoil factor complex from amphibian skin and its functional implications. PLoS One . 2008; 3: e1770.

[13] PFAFFL M W. A new mathematical model for relative quantification in real-time RT-PCR. Nucleic Acids Res 2001; 29: e45. http://dx.doi.org/10.1093/nar/29.9.e45

[14] MOSS S F, LEE J W, SABO E, RUBIN A K, ROMMEL J, et al. Decreased expression of gastrokine 1 and the trefoil factor interacting protein TFIZ1/GKN2 in gastric cancer: influence of tumor histology and relationship to prognosis. Clin Cancer Res . 2008; 14: 4161-4167. http://dx.doi.org/10.1158/10780432.CCR-07-4381

[15] DORSAM R T, GUTKIND J S . G-protein-coupled receptors and cancer. Nat Rev Cancer . 2007; 7: 79-94. http://dx.doi. org/10.1038/nrc2069

[16] DERY O, CORVERA C U, STEINHOFF M, BUNNETT N W . Proteinase-activated receptors: novel mechanisms of signaling by serine proteases. Am J Physiol . 1998; 274: C1429-1452.

[17] HENRIKSON K P, SALAZAR S L, FENTON J W 2ND, PENTECOST B T. Role of thrombin receptor in breast cancer invasiveness. Br J Cancer . 1999; 79: 401-406. http://dx.doi. org/10.1038/sj.bjc.6690063

[18] D'ANDREA M R, DERIAN C K, SANTULLI R J , ANDRADEGORDON P . Differential expression of protease-activated receptors-1 and -2 in stromal fibroblasts of normal, benign, and malignant human tissues. Am J Pathol . 2001; 158: 20312041. http://dx.doi.org/10.1016/S0002-9440(10)64675-5
[19] YADA K, SHIBATA K, MATSUMOTO T, OHTA M, YOKOYAMA S, et al. Protease-activated receptor- 2 regulates cell proliferation and enhances cyclooxygenase- 2 mRNA expression in human pancreatic cancer cells. J Surg Oncol . 2005; 89: 79-85. http://dx.doi.org/10.1002/jso.20197

[20] MATEJ R, MANDAKOVA P, NETIKOVA I, POUCKOVA $\mathrm{P}$, OLEJAR T . Proteinase-activated receptor-2 expression in breast cancer and the role of trypsin on growth and metabolism of breast cancer cell line MDA MB-231. Physiol Res . 2007; 56: 475-484.

[21] RYDEN L, GRABAU D, SCHAFFNER F, JONSSON P E, RUF W, et al. Evidence for tissue factor phosphorylation and its correlation with protease-activated receptor expression and the prognosis of primary breast cancer. Int J Cancer . 2010; 126: $2330-2340$.

[22] WANG X, LIU H T, LI S, LI K, LIN N, et al. Prognostic value of protease-activated receptor 2 expression in oesophageal squamous cell carcinoma. J Int Med Res . 2010; 38: 1381-1388. http://dx.doi.org/10.1177/147323001003800420

[23] PENG H H, ZHANG X, CAO P G . MMP-1/PAR-1 signal transduction axis and its prognostic impact in esophageal squamous cell carcinoma. Braz J Med Biol Res . 2012; 45: 86-92. http://dx.doi.org/10.1590/S0100-879X2011007500152

[24] JIANG P, YU G Y, ZHANG Y, XIANG Y, HUA H R, et al. Down-regulation of protease-activated receptor 4 in lung adenocarcinoma is associated with a more aggressive phenotype. Asian Pac J Cancer Prev . 2013; 14: 3793-3798. http://dx.doi. org/10.7314/APJCP.2013.14.6.3793

[25] FUJIMOTO D, HIRONO Y, GOI T, KATAYAMA K, HIROSE $\mathrm{K}$, et al. Expression of protease activated receptor-2 (PAR-2) in gastric cancer. J Surg Oncol . 2006; 93: 139-144. http://dx.doi. org/10.1002/jso.20420

[26] GRATIO V, WALKER F, LEHY T, LABURTHE M , DARMOUL D . Aberrant expression of proteinase-activated receptor 4 promotes colon cancer cell proliferation through a persistent signaling that involves Src and ErbB-2 kinase. Int J Cancer . 2009; 124: 1517-1525. http://dx.doi.org/10.1002/ ijc. 24070

[27] TANG R G, HUANG Y Z, YAO L M, XIAO J, LU C, et al. Polymorphisms of transforming growth factor beta 1 (RS\#1800468 and RS\#1800471) and esophageal squamous cell carcinoma among Zhuangese population, China. Gene . 2013; 512: 1-5. http://dx.doi.org/10.1016/j.gene.2012.10.009

[28] SAFAEE A, FATEMIS R, MOGHIMI-DEHKORDI B, GHIASI S, ZALI M R. Epidemiology and histopathological features of esophageal cancer. East Afr J Public Health . 2012; 9: 7-9.

[29] GARINIS G A, PATRINOS G P, SPANAKIS N E, MENOUNOS P G . DNA hypermethylation: when tumour suppressor genes go silent. Hum Genet .2002; 111: 115-127. http://dx.doi. org/10.1007/s00439-002-0783-6

[30] BIRD A P, WOLFFE A P . Methylation-induced repression--belts, braces, and chromatin. Cell. 1999; 99: 451-454. http://dx.doi.org/10.1016/S0092-8674(00)81532-9

[31] HERMAN J G, BAYLIN S B . Promoter-region hypermethylation and gene silencing in human cancer. Curr Top Microbiol Immunol . 2000; 249: 35-54. http://dx.doi.org/10.1007/9783-642-59696-4 3 